\title{
Curcumin Suppresses the Colon Cancer Proliferation by Inhibiting Wnt/ $\beta$-Catenin Pathways via miR-130a
}

\author{
Huiqiang Dou, Renhui Shen, Jianxin Tao, Longchang Huang, Haoze Shi, Hang Chen, \\ Yixin Wang and Tong Wang*
}

Department of Endoscopy Surgery, Wuxi People's Hospital Affiliated to Nanjing Medical University, Wuxi, China

OPEN ACCESS

Edited by:

Pierre Sonveaux

Université catholique de Louvain,

Belgium

Reviewed by:

Weicheng Liang,

The Chinese University of Hong Kong,

Hong Kong

Paolo E. Porporato,

Università degli Studi di Torino, Italy

*Correspondence:

Tong Wang

aanti@163.com

Specialty section:

This article was submitted to Pharmacology of Anti-Cancer Drugs, a section of the journal

Frontiers in Pharmacology

Received: 21 July 2017 Accepted: 13 November 2017 Published: 24 November 2017

Citation:

Dou H, Shen R, Tao J, Huang L, Shi $H$, Chen $H$, Wang $Y$ and Wang $T$

(2017) Curcumin Suppresses

the Colon Cancer Proliferation by Inhibiting Wnt/ $\beta$-Catenin Pathways via miR-130a. Front. Pharmacol. 8:877. doi: 10.3389/fphar.2017.00877
Curcumin exhibits anti-tumor effects in several cancers, including colorectal carcinoma (CRC), but the detailed mechanisms are still unclear. Here we studied the mechanisms underlying the anti-tumor effect of curcumin in colon cancer cells. SW480 cells were injected into mice to establish the xenograft tumor model, followed by evaluation of survival rate with the treatment of curcumin. The expression levels of $\beta$-catenin, Axin and TCF4 were measured in the SW480 cells in the absence or presence of curcumin. Moreover, miRNAs related to the curcumin treatment were also detected in vitro. Curcumin could suppress the growth of colon cancer cells in the mouse model. This anti-tumor activity of curcumin was exerted by inhibiting cell proliferation rather than promoting cell apoptosis. Further study suggested that curcumin inhibited cell proliferation by suppressing the Wnt/ $\beta$-catenin pathway. MiR-130a was down-regulated by curcumin treatment, and overexpressing miR-130a could abolish the anti-tumor activity of curcumin. Our study confirms that curcumin is able to inhibit colon cancer by suppressing the $\mathrm{Wnt} / \beta$-catenin pathways via miR-130a. MiR-130a may serve as a new target of curcumin for $\mathrm{CRC}$ treatment.

Keywords: colon cancer, curcumin, Wnt signaling, anti-tumor, miRNA

\section{INTRODUCTION}

Colorectal carcinoma (CRC) is the second most common malignancy in China (Li and Ma, 2014). Advanced high-grade CRC has a five-year survival rate of less than 10\% (Jeong and Cairns, 2013; Wang et al., 2013). According to the Global Cancer Statistics, the incidence rate of CRC is rising in East Asia (Center et al., 2009). Current treatments of CRC include surgery and chemotherapy (Mishra et al., 2013). Chemotherapeutic agents such as capecitabine and oxaliplatin are categorized as "special drugs" for the treatment of stage III/IV CRC (Chiu et al., 2014). However, the efficacy of current treatments are compromised by the high recurrence rate and poor prognosis (Fleming et al., 2012). Thus, it is in urgent need to find new therapeutic strategies for CRC treatment.

The Wnt pathway is categorized as canonical and non-canonical signaling pathways, the latter of which is $\beta$-catenin independent (Bahrami et al., 2017). On the other hand, for the canonical pathway, in the absence of Wnt ligands, free cytoplasmic $\beta$-catenin is destabilized and degraded by a destruction complex composed by APC, Axin, casein kinase 1a (CK1a), and glycogen synthase kinase-3b (GSK3b). Interaction of Wnt with Frizzled and indicates the activation of 
Wnt signaling. When Disheveled (Dvl) and Axin are recruited to the cell membrane and GSK3b is suppressed, $\beta$-catenin is released from of the destruction complex and accumulates in the cytoplasm. Accumulated cytoplasmic $\beta$-catenin can be translocated into the nucleus where it binds to various transcription factors, such as T-cell factor (TCF) and lymphoid enhancer factor1 (LEF-1), to activate Wnt target genes (Barker, 2008; Zhan et al., 2017). In most CRC patients, there is at the least one mutation in the Wnt signaling cascade genes, such as the $\beta$-catenin and APC (Bahrami et al., 2017). About $80 \%$ patients with sporadic colorectal cancers carry APC mutation, while half of colon cancer patients with wild-type APC carry mutations in $\beta$-catenin (Morin et al., 1997). In summary, the Wnt/ $\beta$-catenin pathway becomes the therapeutic target for treating CRC (Xiao et al., 2003).

Curcumin is the major yellow pigment and spice in turmeric and curry, and is a powerful anti-cancer agent (Zhou et al., 2017). Studies indicate that curcumin has anti-tumor effects on several
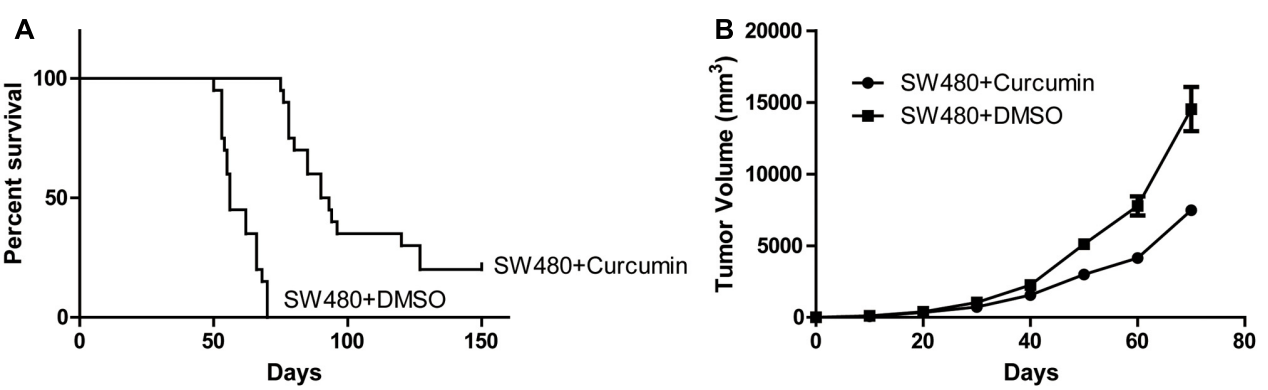

FIGURE 1 | Curcumin suppressed colon cancer. (A) Tumor generated by SW480 with different treatment as indicated was measured in diameters and calculated to volume according to the time point. $n=20$ for each group. (B) Survival curve of the mice treated with curcumin or DMSO. Each group contains 20 mice.

A
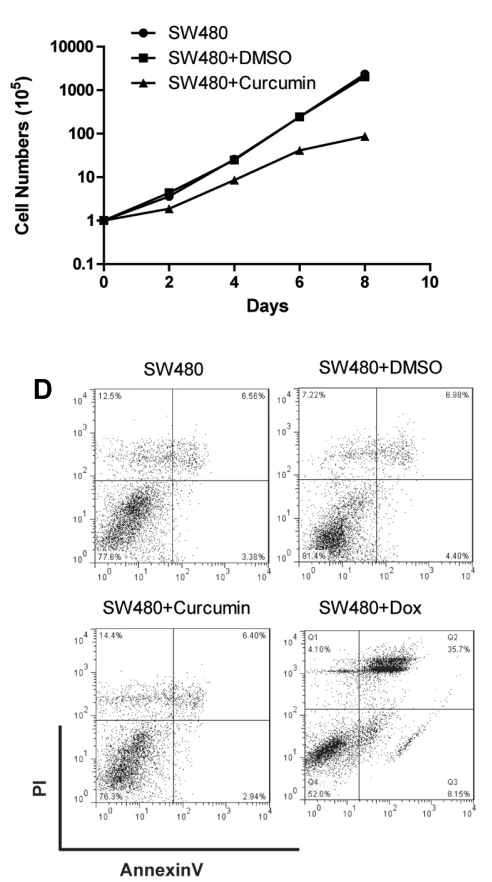

B
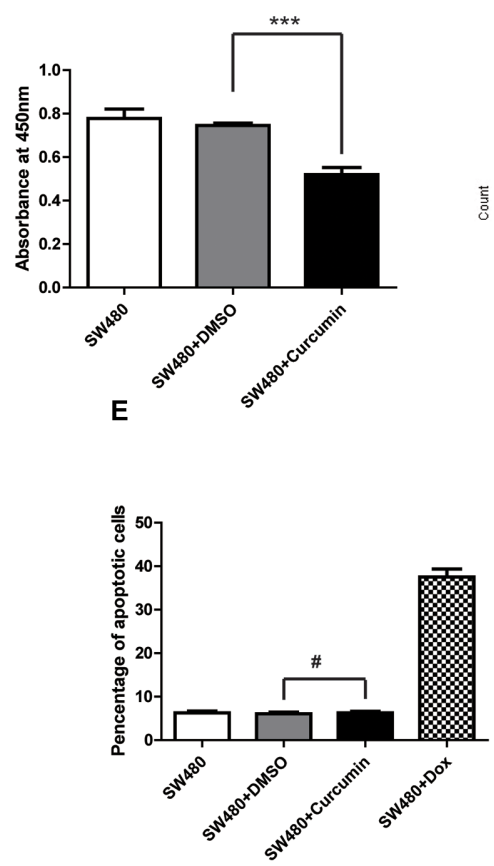

C
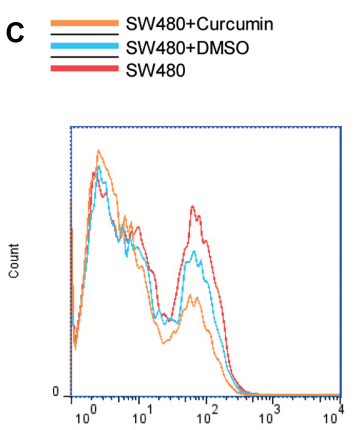

FIGURE 2 | Curcumin inhibited the cell proliferation of SW480. (A) Cell proliferation of different groups as indicated was determined by cell counting. The concentration of curcumin was $40 \mu \mathrm{M}$. Data were represented as mean $\pm \mathrm{SD} ; n=3$ independent experiments. (B) CCK-8 kit was used to evaluate the viability of each group of the cells as indicated. Data were represented as mean \pm SD; $n=3$ independent experiments. ${ }^{* * *} p<0.001$. (C) Cell proliferation was detected by BrdU incorporation assay and $n=3$ independent experiments and this panel presented one of these repeats. (D) The apoptosis of the SW480 cells with different treatment as indicated was determined by using the Annexin-V-FITC \& PI Apoptosis Kit and assessed by flow cytometry. $n=3$ independent experiments and this panel presented one of these repeats. (E) Statistic of percentage of the apoptosis cells performed in (D). Data showed the Annexin-V and PI double positive cells. Data were represented as mean $\pm \mathrm{SD} ; n=3$ independent experiments. ${ }^{\#} p>0.05$. 
cancers, including CRC (Tong et al., 2016; Guo et al., 2017; Simental-Mendia et al., 2017; Xu et al., 2017), but the detailed mechanisms are still unclear.

In this study, we found that curcumin could suppress colon cancer both in vitro and in vivo, supporting curcumin as a chemotherapy candidate for colon cancer. The antitumor activity of curcumin was demonstrated by repressing the $\mathrm{Wnt} / \beta$-catenin pathway and inhibiting the proliferation of colon cancer cells. This process was regulated by repressing the expression of microRNA (miR)-130a, and overexpressing miR130 a could completely abolish the curcumin-induced anti-tumor activity in colon cancer.

\section{MATERIALS AND METHODS}

\section{Reagents}

Dulbecco's Modified Eagle Medium (DMEM) was bought from GIBCO (Pleasanton, CA, United States), and the fetal calf serum (FCS) was purchased from HyClone Laboratories (Logan, UT, United States). Anti-human $\beta$-catenin, Axin, TCF4, GAPDH antibodies and curcumin were purchased from Sigma-Aldrich (St. Louis, MO, United States). Cell counting kit-8 was purchased from Dojindo Laboratories (Tokyo, Japan).

\section{RNA Extraction and q-PCR}

Total RNA was isolated with a mirVana ${ }^{\mathrm{TM}}$ miRNA Isolation Kit (Ambion, Austin, TX, United States). All primers for detecting miRNA expression were designed and synthesized by Genscript Co. Ltd. (Nanjing, China) using the mirVana ${ }^{\mathrm{TM}}$ qRT-PCR Primer Sets. U6 was used as internal control to normalize the expression levels of each miRNA. The fold change in miRNA expression was determined by comparative CT method.

\section{Cell Culture}

The colon cancer cell line SW480 was obtained from American Type Culture Collection (Manassas, VA, United States) and cultured in DMEM supplemented with 10\% FCS and 1\% penicillin/streptomycin (Sigma-Aldrich).

\section{Flow Cytometry and Apoptosis}

Cells with different treatments were washed twice in FACS medium (phosphate buffered saline containing 1\% FCS and $0.1 \%$ $\mathrm{NaN}_{3}$ ). Then the cells were washed three times with Annexin $\mathrm{V}$ binding buffer. After centrifugation, the supernatant was discarded. Cells were incubated for $30 \mathrm{~min}$ at $4^{\circ} \mathrm{C}$ with FITCAnnexin $\mathrm{V}$ according to standard procedure. PI was added before testing. Fluorescence was measured using a FACSCalibur (Becton Dickinson, San Diego, CA, United States), and data were analyzed by the Flowjo Software (Becton Dickinson, San Diego, CA, United States).

\section{Western Blot Analysis}

$1 \times 10^{7}$ cells were lysed in a buffer containing $20 \mathrm{mM}$ Tris$\mathrm{HCl}$ (pH 7.6), $250 \mathrm{mM} \mathrm{NaCl}, 0.5 \%$ NP-40, 3 mM EDTA, and $1.5 \mathrm{mM}$ EGTA with $10 \mu \mathrm{g} / \mathrm{ml}$ Aprotinin, $10 \mu \mathrm{g} / \mathrm{ml}$ leupeptin, $1 \mathrm{mM}$ DTT, $1 \mathrm{mM}$ PNPP and $0.1 \mathrm{mM} \mathrm{Na}_{3} \mathrm{VO}_{4}$ as protease and phosphatase inhibitor. After centrifugation, cell lysates (100 $\mu \mathrm{g} /$ lane) were subjected to $10 \%$ SDS-PAGE and transferred onto polyvinylidene difluoride membranes (Roche, Germany). The membranes were blocked for $1 \mathrm{~h}$ in TBST (25 mM Tris- $\mathrm{HCl}, \mathrm{pH} 7.6,125 \mathrm{mM} \mathrm{NaCl}, 0.1 \%$ Tween-20) containing $5 \%$ nonfat dried milk, and then incubated with appropriate antibodies diluted in TBST containing 5\% nonfat dried milk at $4^{\circ} \mathrm{C}$ overnight. HRP-conjugated secondary antibodies were from Sigma. Protein bands were detected by the Immobilon Western

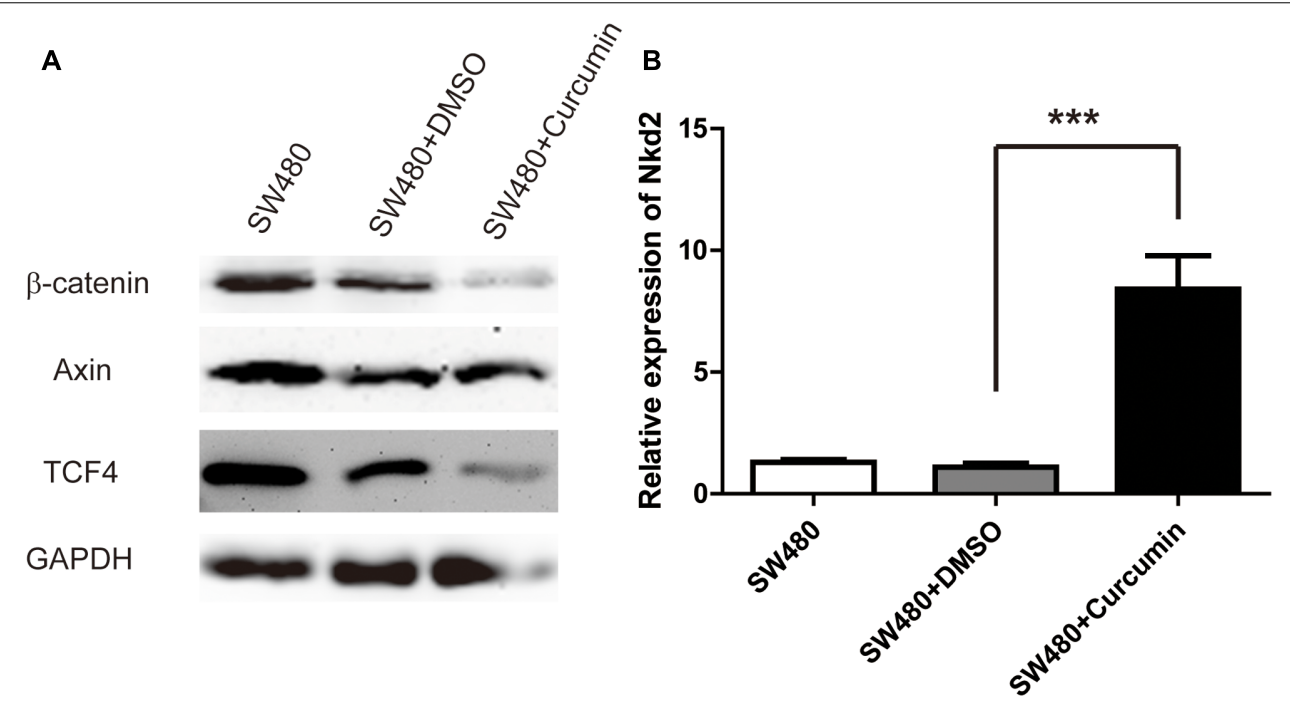

FIGURE 3 | Curcumin inhibited Wnt/ $\beta$-catenin pathways. (A) Western blot analysis of the protein expression of $\beta$-catenin, axin, TCF4, and GAPDH in SW480 cells following curcumin treatment for $24 \mathrm{~h}$. The concentrations of curcumin was $40 \mu \mathrm{M} . n=3$ independent experiments and this panel presented one of these repeats. (B) RT-q-PCR of the mRNA level of Nkd2 in SW480 cells with the treatments as indicated. Data were represented as mean \pm SD; $n=3$ independent experiments. ${ }^{* * *} p<0.001$ 


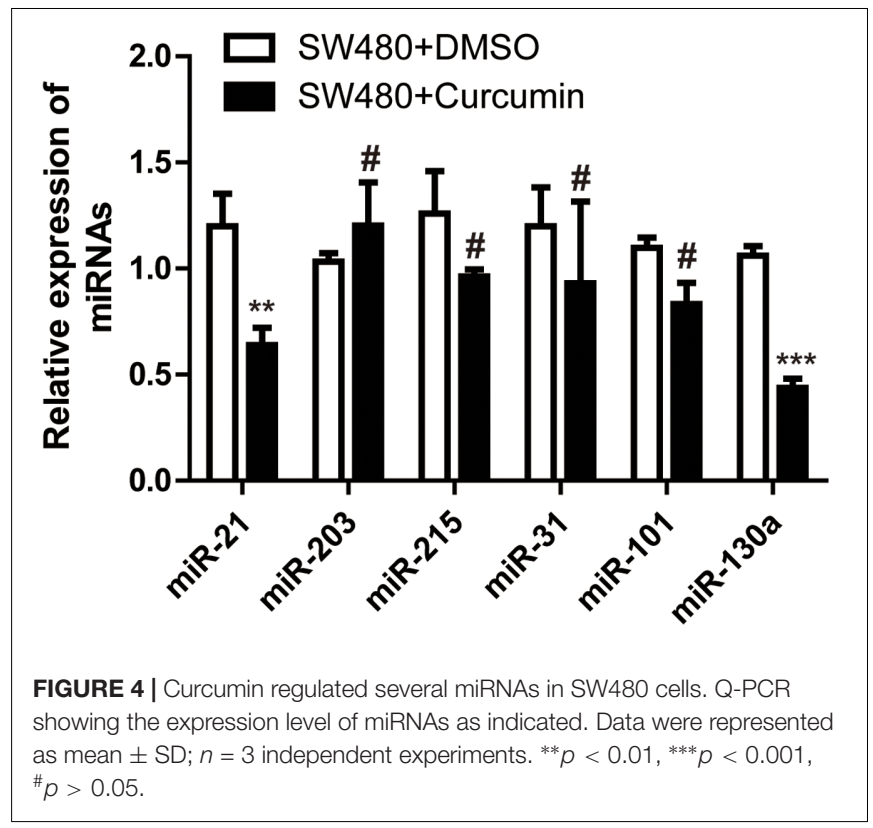

Chemiluminescent HRP Substrate (Millipore, United States) and images were taken by FluorChem FC2 System (Alpha Innotech Corporation, United States).

\section{Cell Proliferation Assay}

The cell proliferation was detected by cell counting or by Cell Counting Kit (CCK)-8 according to the manufacturer's instructions.

\section{BrdU Incorporation Assay}

The 5-bromo-2'-deoxyuridine (BrdU) (B5002, Sigma) was incorporated into cellular DNA during cell proliferation. PEconjugated BrdU mouse monoclonal antibody (\#50230, Cell signaling Technology) was used to label the BrdU. After removing labeling medium, cells were fixed and DNA was denatured with fixing/denaturing solution. FACS was used to detect the incorporated BrdU by the PE channel.

\section{Animals and Surgical Procedures}

6-week-old female nude mice were provided by Animal Center in Nanjing Medical University. All protocols, described below, were approved by the Animal Care and Use Committee at Wuxi People's Hospital Affiliated to Nanjing Medical University. $1 \times 10^{5}$ SW480 cells suspended in $1 \mathrm{ml}$ DMEM were injected by axillary inoculation. Curcumin was injected by intraperitoneal (i.p.) injection at the dose of $200 \mathrm{mg} / \mathrm{kg}$ for 5 days after tumor generation. Mice were monitored daily to record the survival rate.

\section{Statistical Analysis}

Results were expressed as mean $\pm \mathrm{SD}$. The one-way analysis of variance (ANOVA) was used to determine significant differences between the means of three or more independent groups, and the Student's $t$-test was to examine the significance between two groups. $P$-values $(p)$ were indicated in each figure.

\section{RESULTS}

\section{Curcumin Exhibited Anti-tumor Activity}

Since curcumin was reported to have anti-tumor effects on colon cancer, we first used colon cancer cell line SW480 to generate the in vivo animal model by subcutaneous injection. The mice with the tumor receiving intraperitoneal injection of curcumin showed prolonged life span compare to the control group receiving vehicle injection (Figure 1A). Meanwhile, the tumors in the curcumin group grew slower than the control group (Figure 1B). These data indicated that curcumin exhibited anti-tumor activity in the in vivo mouse model generated by the SW480 cell line.
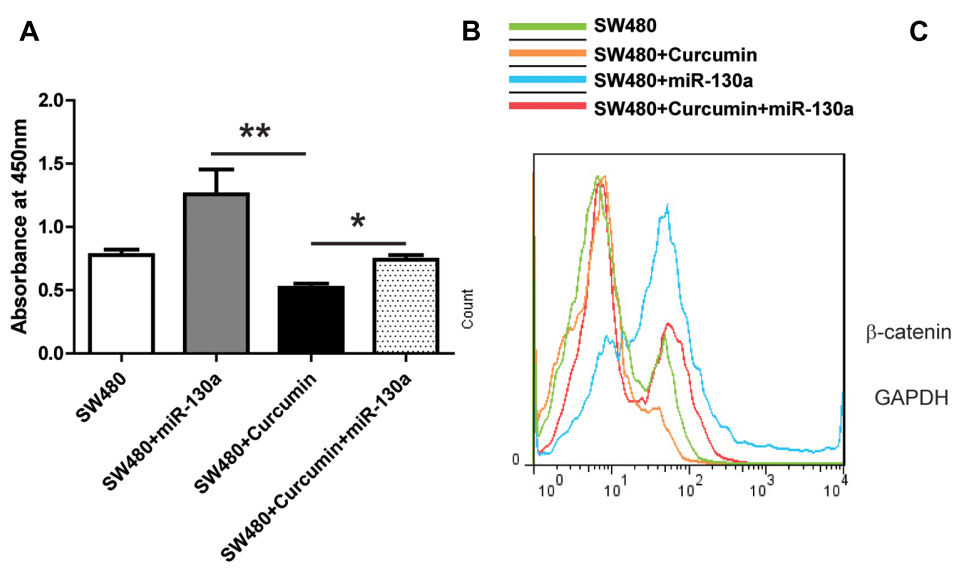

C

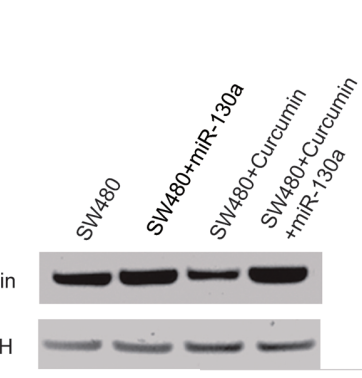

FIGURE 5 | Curcumin inhibited Wnt pathway via miR-130a. (A) CCK-8 kit was used to evaluate the viability of each group of the cells as indicated. Data were represented as mean $\pm \mathrm{SD} ; n=3$ independent experiments. ${ }^{*} p<0.05,{ }^{* *} p>0.05$. (B) Cell proliferation was detected by BrdU incorporation assay and $n=3$ independent experiments and this panel presented one of these repeats. (C) Western blot analysis of the protein expression of $\beta$-catenin and GAPDH in SW480 cells. $n=3$ independent experiments and this panel presented one of these repeats. 

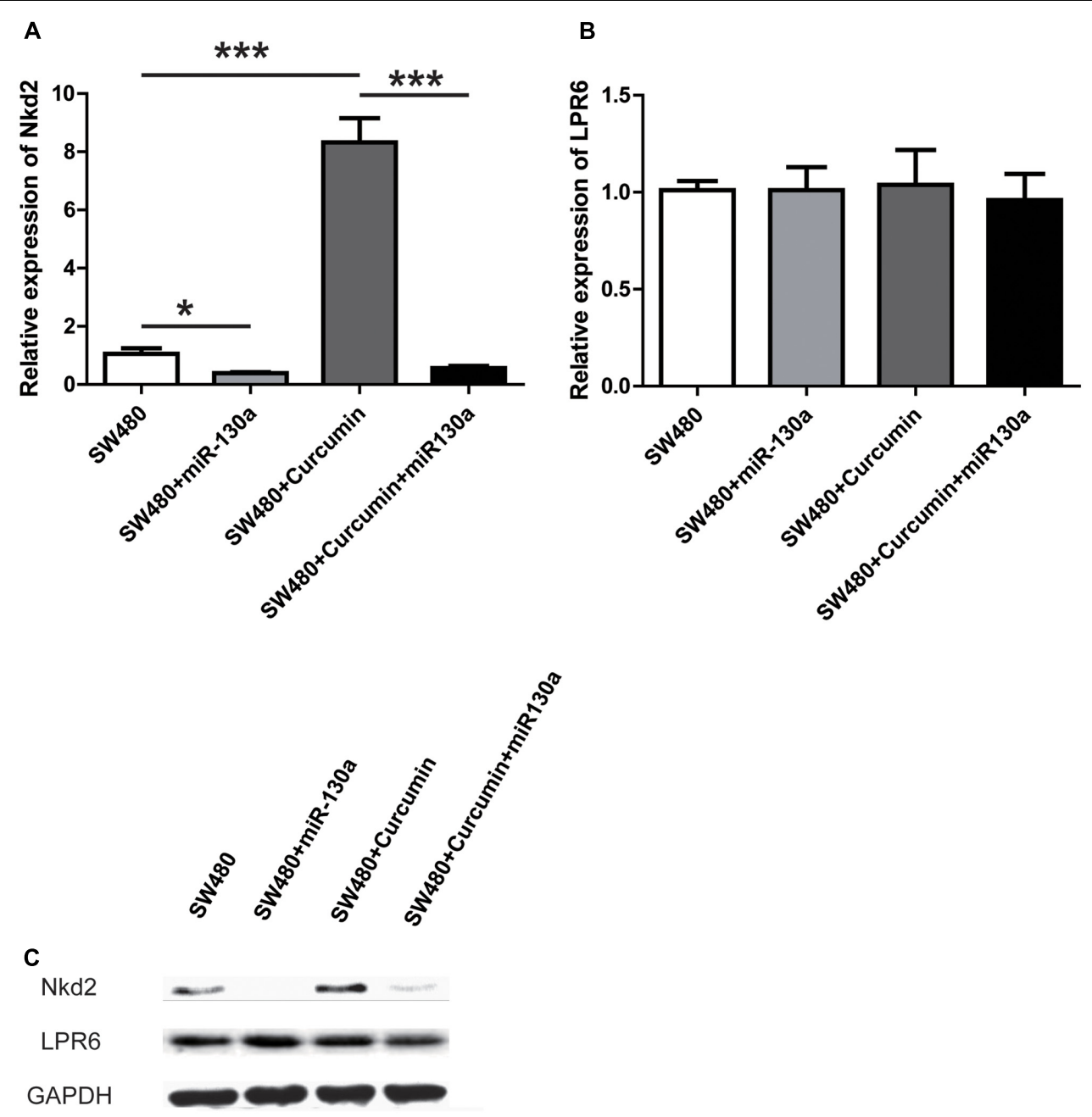

FIGURE 6 | miR-130 abolished the anti-proliferation effect of curcumin by downregulating nkd2. (A) RT-q-PCR of the mRNA level of Nkd2 in SW480 cells with the treatments as indicated. Data were represented as mean $\pm \mathrm{SD} ; n=3$ independent experiments. ${ }^{*} p<0.05,{ }^{* * *} p<0.001$. (B) RT-q-PCR of the mRNA level of LPR6 in SW480 cells with the treatments as indicated. Data were represented as mean \pm SD; $n=3$ independent experiments. (C) Western blot analysis of the protein level of NKD2 and LPR6 in SW480 cells with the treatment as indicated. $n=3$ independent experiments and this panel presented one of these repeats.

\section{Curcumin Suppressed Proliferation of Tumor Cells}

In order to investigate the mechanism underlying the inhibitory effect of curcumin on colon cancer cells, we performed assays to evaluate cell proliferation and apoptosis. In the cell counting assay, we found that the cells treated with curcumin grew much slower, compared to both the control group and the group treated with DMSO (Figure 2A), which indicated that curcumin inhibited cell proliferation in vitro. Consistent with cell counting assay, results from the CCK- 8 kit for determining the viability of the colon cancer cells also indicated that the curcumintreated cells showed the lowest viability (Figure 2B). Next, we tested the apoptosis of SW480 cells with different treatments. Percentages of the Annexin V-positive apoptotic cells with curcumin treatment did not display any difference compared to the control cells (Figures $2 \mathbf{C}-\mathbf{E}$ ). These results indicated that curcumin suppressed colon cancer cells by inhibiting proliferation rather than promoting apoptosis. It is worth noting that similar results could be observed in another colon cancer cell line HCT116 (Supplementary Figures S1A-C).

\section{Curcumin Inhibited Wnt/ $\beta$-Catenin Pathways}

The Wnt/ $\beta$-catenin pathways play an important role in colon cancer by promoting cell proliferation. Therefore, we asked whether the anti-tumor activity of curcumin was mediated through Wnt/ $\beta$-catenin signaling. Western bolt analysis showed that the expression level of $\beta$-catenin was decreased after curcumin treatment, whereas the expression level of Axin was unchanged (Figure 3A). Since $W n t / \beta$-catenin pathways have many negative regulators, such as $\mathrm{Nkd} 2$, we assessed the mRNA level of $\mathrm{Nkd} 2$ by RT-qPCR, and found that $\mathrm{Nkd} 2$ was upregulated by curcumin treatment (Figure 3B). We then proceeded to assess the Wnt target gene TCF4. Although TCF is a transcription factor 


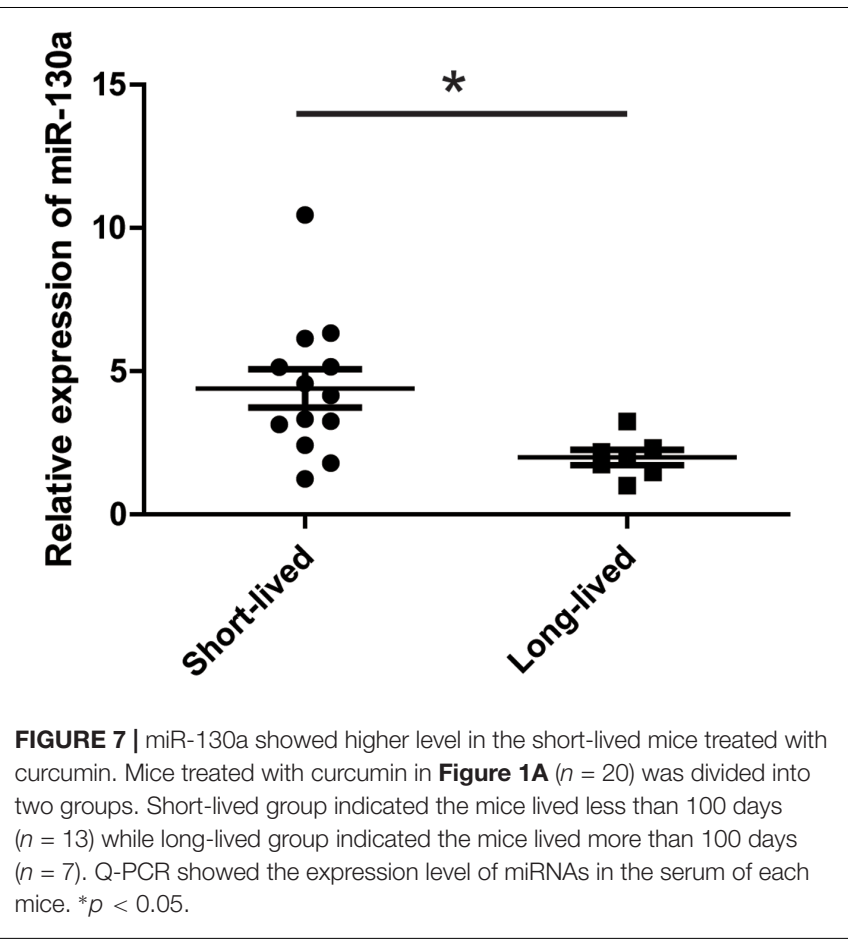

in the $\mathrm{Wnt} / \beta$-catenin signaling, it is also a Wnt target gene. Consistent with our observations on Nkd 2 and $\beta$-catenin, TCF4 was also down-regulated by curcumin treatment. The above results demonstrated that curcumin inhibited colon cancer cell proliferation through suppressing the $\mathrm{Wnt} / \beta$-catenin signaling pathways.

\section{Curcumin Suppressed the Wnt/ $\beta$-Catenin Pathway via miR-130a}

In order to reveal the mechanism underlying curcumin regulation on the $\mathrm{Wnt} / \beta$-catenin signaling, we tested several miRNAs reported to be upregulated in CRC. q-PCR showed that with curcumin treatment, miR-21 and miR-130a were down-regulated (Figure 4). MiR-21 has been reported to be involved in colon cancer, whereas the function of miR-130a is not clear. Therefore, we overexpressed miR-130a in SW480 cells and treated the cells with curcumin, followed by determining cell proliferation and $\beta$-catenin expression level. Interestingly, in the presence of miR-130a, cell proliferation was restored to similar level as the control group (Figure 5A), and $\beta$-catenin level was also returned to normal level (Figure 5B). These results indicated that curcumin suppressed the $\mathrm{Wnt} / \beta$-catenin pathway via inhibiting miR-130a.

Furthermore, we investigated potential mechanism underlying miR-130a involvement in Wnt signaling. We first evaluated $\mathrm{Nkd} 2$ expression, since it has been shown to be up-regulated by curcumin treatment (Figure 3). Our results showed that $\mathrm{miR}-130 \mathrm{a}$ could repress the expression of $\mathrm{Nkd} 2$ in both mRNA and protein levels (Figures 6A,C). We also predicted the targets of miR-130a through online tool $^{1}$, among which LPR6 was identified to be related to the Wnt pathway. Therefore, we tested the level of LPR6 after miR-130a overexpression in the absence or presence of curcumin treatment. Unfortunately, neither the mRNA nor the protein level of LPR6 was changed (Figures 6B,C). We observed similar pattern in these proteins in another colon cancer cell line HCT116 (Supplementary Figure S1D). However, none of the predicted target genes of miR-130a were found to be potential indirect regulators of $\mathrm{Nkd} 2$ (data not shown), and 5'-UTR of $\mathrm{Nkd} 2$ was also not found to be targeted by miR-130a using TargetscanHuman $7.1^{2}$.

These data suggested that miR-130 might act to antagonize curcumin's anti-tumor effect. We therefore examined the serum level of miR-130a in mice treated with curcumin. We divided the mice into two sub-groups: short-lived group ( $<100$ days, 13 mice) and long-lived group (>100 days, 7 mice, 4 of which survived more than 150 days). The serum level of miR-130a was significantly higher in the short-lived group than that of the long-lived group of mice (Figure 7), which confirmed that miR-130a functioned to antagonize curcumin's anti-tumor effect.

\section{DISCUSSION}

Curcumin, the major curcuminoid and the most active component in turmeric, is a biologically active phytochemical (Goel et al., 2008). Curcumin is also reported to be beneficial in arthritis (Ahmed et al., 2005; Chandran and Goel, 2012), neurodegenerative diseases (Ramassamy, 2006; Cole et al., 2007) and autoimmune conditions (Bright, 2007). Increasing evidences have shown that curcumin exhibits anti-tumor activity (Aggarwal et al., 2003; Kunnumakkara et al., 2008; Kasi et al., 2016) in several cancers, including CRC (Tong et al., 2016; Guo et al., 2017; Simental-Mendia et al., 2017; Xu et al., 2017), but the detailed mechanism is still unclear.

In this study, we first confirmed the anti-tumor activity of curcumin in colon cancer in vivo using a mouse model. Curcumin exerts its anti-tumor activity by inhibiting proliferation rather than promoting apoptosis of the colon cancer cells. Then we attempted to identify the signaling pathway involved in this process. In particular, curcumin affects several signaling pathways known to be important for solid and blood cancers, such as the PI3k/Akt-1/mTOR pathway (Sokolosky et al., 2011; McCubrey et al., 2012; Zhao et al., 2016; Zhu et al., 2017), the Ras/Raf/MEK/ERK pathway (McCubrey et al., 2012), the GSK3beta pathway (Yun et al., 2015), p53 activity (Sidhar and Giri, 2017), and NF- $\kappa B$ pathways (Marin et al., 2007). In addition, the Wnt signaling pathway is one of the key dysregulated pathways in colorectal cancer, which increases cell proliferation and resistance to chemotherapy (Park et al., 2012; Moradi et al., 2017). Therefore we tested Wnt signaling in the colon cancer cells treated with curcumin, and our results showed that curcumin could inhibit the Wnt signaling by down-regulating $\beta$-catenin, which was

\footnotetext{
${ }^{1}$ http://www.microrna.org

${ }^{2}$ http://www.targetscan.org/vert_71/
} 
mediated by up-regulating the Wnt signaling negative regulator $\mathrm{Nkd}$ 2. These results demonstrated that curcumin exerted antitumor activity by inhibiting Wnt signaling to inhibit the cell proliferation.

Next, we investigated the mechanism underlying curcumin effect on Wnt signaling. In addition to the gene expression studies (Ramachandran et al., 2005; Teiten et al., 2009; Huminiecki et al., 2017), we noticed some microRNA (miRNA) studies (Ye et al., 2015; Zhou et al., 2017) implicating miRNAs in the function of curcumin. MiRNAs are short non-coding RNAs of 20-24 nucleotides that play important roles in many biological pathways including processes related to cancer, such as proliferation, cell cycle control, apoptosis, differentiation, migration and metabolism. We therefore examined the miRNAs reported to be involved in colon cancer, and found that only miR-21 and miR-130a were affected by curcumin. Since miR-130a was a novel miRNA that had few reported functions in colon cancer, we focused on the role of miR-130a in curcumin action in colon cancer. We overexpressed miR-130a in SW480 cells and treated them with curcumin. The results showed that curcumin could suppress the proliferation of SW480 cells. In the presence of miR-130a, cell proliferation was restored to similar level as the control cells. We also assessed the $\mathrm{Wnt} / \beta$-catenin signaling in the colon cancer cells. Consistent with the proliferation results, the protein level of $\beta$-catenin was also restored to normal level.

Subsequently, we found that miR-130a could repress the expression level of $\mathrm{Nkd} 2$, which could be up-regulated by curcumin. These results suggested that miR-130a may regulate the Wnt pathway by inhibiting Nkd2. However, none of the predicted target genes of miR-130a were found to be potential indirect regulators of $\mathrm{Nkd} 2$, therefore the exact mechanism under this inhibition still elusive, and further investigations are warranted. It has been reported that miR-130a expression is disregulated in several types of cancer (Zhang et al., 2017), including colon cancer (Kara et al., 2015). Increasing targets of miR-130a have been identified. For example, TNF$\alpha$ can activate NF- $\mathrm{B}$ activity to upregulate miR-130a, which in turn targets and inhibits TNF- $\alpha$ expression as a negative feedback loop. This negative feedback regulation of $N F-\kappa B / m i R-$ $130 \mathrm{a} / \mathrm{TNF}-\alpha / \mathrm{NF}-\kappa \mathrm{B}$ may provide insight into the carcinogenesis of cervical cancer (Zhang et al., 2014). MiR-130a also increases drug resistance by regulating RUNX3 and Wnt signaling in cisplatin-treated hepatocellular carcinoma cells (Xu et al., 2012). However, little is known about the targets of miR-130a in colon cancer. Here our results proposed that Wnt pathway might be a potential target for miR-130a in colon cancer, but its direct target still needs to be identified in further work.

Furthermore, we have verified that curcumin exhibits anti-tumor activity in colon cancer, which was exerted by

\section{REFERENCES}

Aggarwal, B. B., Kumar, A., and Bharti, A. C. (2003). Anticancer potential of curcumin: preclinical and clinical studies. Anticancer Res. 23, 363-398. inhibiting the $\mathrm{Wnt} / \beta$-catenin signaling pathway to suppress cell proliferation in the colon cancer cells. Our results further suggested that curcumin could affect levels of several miRNAs in colon cancer cells. Among these miRNAs, miR-130a may be important for cancer formation because overexpressing miR130a could restore the proliferation of curcumin-suppressed cancer cells back to normal. Meanwhile, the expression of Wnt signaling pathway component, $\beta$-catenin, was also restored to similar level as the original cancer cells. These results indicated that curcumin inhibited the Wnt signaling by repressing the expression level of the miR-130a. Furthermore, we tested the serum level of miR-130a in the experimental mice. We found that the short-lived mice had higher level of miR-130a in their serum than the long-lived mice. This suggested that miR130a might contribute to the resistance of colon cancer cells to chemotherapy. Our study supports miR-130a as a novel target in the treatment of colon cancer. Taken together our earlier clinical study where high miR-130a expression level was significantly associated with poor clinical outcome (Kara et al., 2015), results in our current study suggests that when agent like curcumin is used to treat colon cancer, therapies inhibiting miR-130a may be combined for better clinical efficacy.

\section{CONCLUSION}

Curcumin suppresses colon cancer by inhibiting Wnt/ $\beta$-catenin pathway via miR-130a. MiR-130a may serve as a new target for CRC treatment.

\section{AUTHOR CONTRIBUTIONS}

HD, RS, JT, LH, HS, HC, and YW performed the experiments and analyzed the data. TW wrote the manuscript and designed the study.

\section{FUNDING}

This work was supported by grants from the National Natural Sciences Foundation of China (No. 81371683/H1819), Clinical Medicine Project of Jiangsu Province (BL2014023).

\section{SUPPLEMENTARY MATERIAL}

The Supplementary Material for this article can be found online at: https://www.frontiersin.org/articles/10.3389/fphar. 2017.00877/full\#supplementary-material

Ahmed, S., Anuntiyo, J., Malemud, C. J., and Haqqi, T. M. (2005). Biological basis for the use of botanicals in osteoarthritis and rheumatoid arthritis: a review. Evid. Based Complement. Alternat. Med. 2, 301-308. doi: 10.1093/ecam/ neh117 
Bahrami, A., Amerizadeh, F., Shahidsales, S., Khazaei, M., GhayourMobarhan, M., Sadeghnia, H. R., et al. (2017). Therapeutic potential of targeting Wnt/beta-Catenin pathway in treatment of colorectal cancer: rational and progress. J. Cell. Biochem. 118, 1979-1983. doi: 10.1002/jcb. 25903

Barker, N. (2008). The canonical Wnt/beta-catenin signalling pathway. Methods Mol. Biol. 468, 5-15. doi: 10.1007/978-1-59745249-6_1

Bright, J. J. (2007). Curcumin and autoimmune disease. Adv. Exp. Med. Biol. 595, 425-451. doi: 10.1007/978-0-387-46401-5_19

Center, M. M., Jemal, A., and Ward, E. (2009). International trends in colorectal cancer incidence rates. Cancer Epidemiol. Biomarkers Prev. 18, 1688-1694. doi: 10.1158/1055-9965.EPI-09-0090

Chandran, B., and Goel, A. (2012). A randomized, pilot study to assess the efficacy and safety of curcumin in patients with active rheumatoid arthritis. Phytother. Res. 26, 1719-1725. doi: 10.1002/ptr.4639

Chiu, J., Tang, V., Leung, R., Wong, H., Chu, K. W., Poon, J., et al. (2014). Efficacy and tolerability of adjuvant oral capecitabine plus intravenous oxaliplatin (XELOX) in Asian patients with colorectal cancer: 4-year analysis. Asian Pac. J. Cancer Prev. 14, 6585-6590. doi: 10.7314/APJCP.2013.14.11. 6585

Cole, G. M., Teter, B., and Frautschy, S. A. (2007). Neuroprotective effects of curcumin. Adv. Exp. Med. Biol. 595, 197-212. doi: 10.1007/978-0-38746401-5_8

Fleming, M., Ravula, S., Tatishchev, S. F., and Wang, H. L. (2012). Colorectal carcinoma: pathologic aspects. J. Gastrointest. Oncol. 3, 153-173. doi: 10.3978/ j.issn.2078-6891.2012.030

Goel, A., Kunnumakkara, A. B., and Aggarwal, B. B. (2008). Curcumin as "Curecumin": from kitchen to clinic. Biochem. Pharmacol. 75, 787-809. doi: 10.1016/j.bcp.2007.08.016

Guo, Y., Su, Z. Y., Zhang, C., Gaspar, J. M., Wang, R., Hart, R. P., et al. (2017). Mechanisms of colitis-accelerated colon carcinogenesis and its prevention with the combination of aspirin and curcumin: transcriptomic analysis using RNA-seq. Biochem. Pharmacol. 135, 22-34. doi: 10.1016/j.bcp.2017. 02.021

Huminiecki, L., Horbanczuk, J., and Atanasov, A. G. (2017). The functional genomic studies of curcumin. Semin. Cancer Biol. 46, 107-118. doi: 10.1016/ j.semcancer.2017.04.002

Jeong, K. E., and Cairns, J. A. (2013). Review of economic evidence in the prevention and early detection of colorectal cancer. Health Econ. Rev. 3:20. doi: 10.1186/2191-1991-3-20

Kara, M., Yumrutas, O., Ozcan, O., Celik, O. I., Bozgeyik, E., Bozgeyik, I., et al. (2015). Differential expressions of cancer-associated genes and their regulatory miRNAs in colorectal carcinoma. Gene 567, 81-86. doi: 10.1016/j.gene.2015. 04.065

Kasi, P. D., Tamilselvam, R., Skalicka-Wozniak, K., Nabavi, S. F., Daglia, M., Bishayee, A., et al. (2016). Molecular targets of curcumin for cancer therapy: an updated review. Tumour Biol. 37, 13017-13028. doi: 10.1007/s13277-016$5183-y$

Kunnumakkara, A. B., Anand, P., and Aggarwal, B. B. (2008). Curcumin inhibits proliferation, invasion, angiogenesis and metastasis of different cancers through interaction with multiple cell signaling proteins. Cancer Lett. 269, 199-225. doi: 10.1016/j.canlet.2008.03.009

Li, L., and Ma, B. B. (2014). Colorectal cancer in Chinese patients: current and emerging treatment options. Onco Targets Ther. 7, 1817-1828. doi: 10.2147/ OTT.S48409

Marin, Y. E., Wall, B. A., Wang, S., Namkoong, J., Martino, J. J., Suh, J., et al. (2007). Curcumin downregulates the constitutive activity of NF-kappaB and induces apoptosis in novel mouse melanoma cells. Melanoma Res. 17, 274-283. doi: 10.1097/CMR.0b013e3282ed3d0e

McCubrey, J. A., Steelman, L. S., Chappell, W. H., Abrams, S. L., Montalto, G., Cervello, M., et al. (2012). Mutations and deregulation of Ras/Raf/MEK/ERK and PI3K/PTEN/Akt/mTOR cascades which alter therapy response. Oncotarget 3, 954-987. doi: 10.18632/oncotarget.652

Mishra, J., Drummond, J., Quazi, S. H., Karanki, S. S., Shaw, J. J., Chen, B., et al. (2013). Prospective of colon cancer treatments and scope for combinatorial approach to enhanced cancer cell apoptosis. Crit. Rev. Oncol. Hematol. 86, 232-250. doi: 10.1016/j.critrevonc.2012.09.014
Moradi, A., Ghasemi, F., Anvari, K., Hassanian, S. M., Simab, S. A., Ebrahimi, S., et al. (2017). The cross-regulation between SOX15 and Wnt signaling pathway. J. Cell. Physiol. 232, 3221-3225. doi: 10.1002/jcp.25802

Morin, P. J., Sparks, A. B., Korinek, V., Barker, N., Clevers, H., Vogelstein, B., et al. (1997). Activation of beta-catenin-Tcf signaling in colon cancer by mutations in beta-catenin or APC. Science 275, 1787-1790. doi: 10.1126/science.275.5307. 1787

Park, S. J., Ahmad, F., Philp, A., Baar, K., Williams, T., Luo, H., et al. (2012). Resveratrol ameliorates aging-related metabolic phenotypes by inhibiting cAMP phosphodiesterases. Cell 148, 421-433. doi: 10.1016/j.cell.2012. 01.017

Ramachandran, C., Rodriguez, S., Ramachandran, R., Raveendran Nair, P. K., Fonseca, H., Khatib, Z., et al. (2005). Expression profiles of apoptotic genes induced by curcumin in human breast cancer and mammary epithelial cell lines. Anticancer Res. 25, 3293-3302.

Ramassamy, C. (2006). Emerging role of polyphenolic compounds in the treatment of neurodegenerative diseases: a review of their intracellular targets. Eur. J. Pharmacol. 545, 51-64. doi: 10.1016/j.ejphar.2006.06.025

Sidhar, H., and Giri, R. K. (2017). Induction of Bex genes by curcumin is associated with apoptosis and activation of p53 in N2a neuroblastoma cells. Sci. Rep. 7:41420. doi: 10.1038/srep41420

Simental-Mendia, L. E., Caraglia, M., Majeed, M., and Sahebkar, A. (2017). Impact of curcumin on the regulation of microRNAs in colorectal cancer. Expert Rev. Gastroenterol. Hepatol. 11, 99-101. doi: 10.1080/17474124.2017.126 8528

Sokolosky, M. L., Stadelman, K. M., Chappell, W. H., Abrams, S. L., Martelli, A. M., Stivala, F., et al. (2011). Involvement of Akt-1 and mTOR in sensitivity of breast cancer to targeted therapy. Oncotarget 2, 538-550. doi: 10.18632/ oncotarget. 302

Teiten, M. H., Eifes, S., Reuter, S., Duvoix, A., Dicato, M., and Diederich, M. (2009). Gene expression profiling related to anti-inflammatory properties of curcumin in K562 leukemia cells. Ann. N. Y. Acad. Sci. 1171, 391-398. doi: 10.1111/j.1749-6632.2009.04890.x

Tong, W., Wang, Q., Sun, D., and Suo, J. (2016). Curcumin suppresses colon cancer cell invasion via AMPK-induced inhibition of NF-kappaB, uPA activator and MMP9. Oncol. Lett. 12, 4139-4146.

Wang, J., Wang, X., Lin, S., Chen, C., Wang, C., Ma, Q., et al. (2013). Identification of kininogen-1 as a serum biomarker for the early detection of advanced colorectal adenoma and colorectal cancer. PLOS ONE 8:e70519. doi: 10.1371/ journal.pone.0070519

Xiao, J. H., Ghosn, C., Hinchman, C., Forbes, C., Wang, J., Snider, N., et al. (2003). Adenomatous polyposis coli (APC)-independent regulation of betacatenin degradation via a retinoid X receptor-mediated pathway. J. Biol. Chem. 278, 29954-29962. doi: 10.1074/jbc.M304761200

$\mathrm{Xu}, \mathrm{B}$., Yu, L., and Zhao, L. Z. (2017). Curcumin up regulates T helper 1 cells in patients with colon cancer. Am. J. Transl. Res. 9, 1866-1875.

Xu, N., Shen, C., Luo, Y., Xia, L., Xue, F., Xia, Q., et al. (2012). Upregulated miR-130a increases drug resistance by regulating RUNX3 and Wnt signaling in cisplatin-treated HCC cell. Biochem. Biophys. Res. Commun. 425, 468-472. doi: 10.1016/j.bbrc.2012.07.127

Ye, M., Zhang, J., Zhang, J., Miao, Q., Yao, L., and Zhang, J. (2015). Curcumin promotes apoptosis by activating the p53-miR-192-5p/215-XIAP pathway in non-small cell lung cancer. Cancer Lett. 357, 196-205. doi: 10.1016/j.canlet. 2014.11.028

Yun, J. H., Park, Y. G., Lee, K. M., Kim, J., and Nho, C. W. (2015). Curcumin induces apoptotic cell death via Oct4 inhibition and GSK-3beta activation in NCCIT cells. Mol. Nutr. Food Res. 59, 1053-1062. doi: 10.1002/mnfr.20140 0739

Zhan, T., Rindtorff, N., and Boutros, M. (2017). Wnt signaling in cancer. Oncogene 36, 1461-1473. doi: 10.1038/onc.2016.304

Zhang, H. D., Jiang, L. H., Sun, D. W., Li, J., and Ji, Z. L. (2017). The role of miR-130a in cancer. Breast Cancer 24, 521-527. doi: 10.1007/s12282-0170776-x

Zhang, J., Wu, H., Li, P., Zhao, Y., Liu, M., and Tang, H. (2014). NF-kappaBmodulated miR-130a targets TNF-alpha in cervical cancer cells. J. Transl. Med. 12:155. doi: 10.1186/1479-5876-12-155

Zhao, G., Han, X., Zheng, S., Li, Z., Sha, Y., Ni, J., et al. (2016). Curcumin induces autophagy, inhibits proliferation and invasion 
by downregulating AKT/mTOR signaling pathway in human melanoma cells. Oncol. Rep. 35, 1065-1074. doi: 10.3892/or.2015. 4413

Zhou, S., Zhang, S., Shen, H., Chen, W., Xu, H., Chen, X., et al. (2017). Curcumin inhibits cancer progression through regulating expression of microRNAs. Tumour Biol. 39:1010428317691680. doi: 10.1177/101042831769 1680

Zhu, F. Q., Chen, M. J., Zhu, M., Zhao, R. S., Qiu, W., Xu, X., et al. (2017). Curcumin suppresses epithelial-mesenchymal transition of renal tubular epithelial cells through the inhibition of Akt/mTOR pathway. Biol. Pharm. Bull. 40, 17-24. doi: 10.1248/bpb.b16-00364
Conflict of Interest Statement: The authors declare that the research was conducted in the absence of any commercial or financial relationships that could be construed as a potential conflict of interest.

Copyright (c) 2017 Dou, Shen, Tao, Huang, Shi, Chen, Wang and Wang. This is an open-access article distributed under the terms of the Creative Commons Attribution License (CC BY). The use, distribution or reproduction in other forums is permitted, provided the original author(s) or licensor are credited and that the original publication in this journal is cited, in accordance with accepted academic practice. No use, distribution or reproduction is permitted which does not comply with these terms. 